\title{
Premenstrual Syndrome as a Sleep Disturbing Factor: A Cross- Sectional Study
}

Övsen Önay ${ }^{1},[M D]$

ORCID: 0000-0002-8009-0311

Canset Aydın², [MD]

ORCID: 0000-0001-6288-636X

\section{ne) ABSTRACT Con}

Objective: To evaluate the lifestyle factors possibly related with premenstrual syndrome which were body mass index, coffee intake, smoking, regular physical exercise, and alcohol consumption, and investigate the impact of these lifestyle factors and premenstrual syndrome on sleep quality.

Methods and Methods: This cross-sectional study included 265 participants, and all applied Pittsburgh Sleep Quality Index and Premenstrual Syndrome Scale questionnaires.

Results: The prevalence of premenstrual syndrome among the participants was $57 \%$ (n:150). Participants with premenstrual syndrome had shorter total sleep time ( $\mathrm{p}: 0.001)$. Also, they needed longer time to fall asleep ( $p: 0.001)$. The Pittsburgh Sleep Quality Index scores of the participants with premenstrual syndrome were higher than those without premenstrual syndorme $(p<0.001)$, indicating poor sleep quality. It was observed that the participants with premenstrual syndrome had more coffee intake (p:0.040) and more regular physical activity ( $p: 0.009)$, which were risk factors of premenstrual syndrome. premenstrual syndrome positivity was associated with increased poor sleep quality in both univariate and multivariate analyses (OR:5.93 95\% Cl: $3.46-$ 10.15, $\mathrm{p}<0.001$; OR:5.61 95\% Cl: 3.19-9.88, $\mathrm{p}<0.001$, respectively). The remaining variables, which were risk factors of premenstrual syndrome, didn't have any statistically significant association with sleep quality.

Conclusion: The important relation between premenstrual syndrome and sleep quality is highlighted. Relief of premenstrual syndrome complaints may lead to better sleep quality and enhancement of quality of life for a woman.

Keywords: Premenstrual syndrome, sleep quality, women's health

https://doi.org/10.32552/2021.ActaMedica.561

Received: 28 January 2021, Accepted: 31 March 2021

Published online: 25 June 2021

\section{INTRODUCTION}

Premenstrual syndrome (PMS) is characterized by repetitive, mild to severe emotional and physical symptoms that develop amid the luteal menstrual cycle and vanish with menstruation [1]. Almost $50-90 \%$ of the women of reproductive age undergo at least one psychological or physical manifestation of premenstrual symptoms, but only $30-40 \%$ of them report PMS symptoms which need treatment $[1,2]$. Although the causes of PMS still remain unknown, lifestyle factors such as coffee intake, alcohol consumption, regular exercise and BMI have been claimed to be related with PMS [3-6]. Basically, PMS affects women's quality of life negatively [7] and may lead to the increased use of healthcare system, which in turn may cause economic burden; therefore, a greater understanding of this syndrome by clinicians is required $[8,9]$. Furthermore, impairment of quality of life (QOL) leads to perceived poorer sleep quality [10]. A good sleep is important for the physical and 
psychological health of a woman. Poor quality of sleep and sleep disruptions caused by PMS could adversely affect QOL by reducing productivity, socialization, and daily functioning. In this respect, we aimed to evaluate the lifestyle factors related with PMS and to investigate the impact of these lifestyle factors and PMS on sleep quality.

\section{MATERIALS AND METHODS}

\section{Study Design and Subjects}

This cross-sectional study was conducted between November and December 2019. The study protocol was approved by the Ethics Committee for Research of Medicana International Ankara Hospital and was conducted in accordance with the principles of Declaration of Helsinki. The participants of this analysis were randomized from our hospital's women healthcare workers, and they were asked to fill out self-administered questionnaires the instructions of which had been explained to them in detail beforehand. All volunteers provided informed consent before participating. The participants consisted of 265 women aged between 18 and 45 . Exclusion criteria were any failure to completely fill out the questionnaires, being above 45 years old, not having regular menstrual cycles (periods of 2135 days), having amenorrhea, having night shifts, taking oral contraceptive, hormonal therapy or any prescribed medications for the treatment of PMS, being pregnant, and breast feeding.

\section{Self-administered Questionnaires}

In addition to the demographic and lifestyle data of the participants, our test battery comprised two questionnaires, which were Pittsburgh Sleep Quality Index (PSQI) and Premenstrual Syndrome Scale (PMSS).

The demographic and Lifestyle data collected from the participants comprised age, weight $(\mathrm{kg})$, height $(m)$, coffee intake, smoking, regular physical exercise, and alcohol consumption. BMI was calculated and classified according to WHO 2019 classification criteria $\left(<18.5 \mathrm{~kg} / \mathrm{m}^{2}\right.$ : underweight; $18.5-24.99 \mathrm{~kg} / \mathrm{m}^{2}$ : normal weight; $25-29.9 \mathrm{~kg} /$ $\mathrm{m}^{2}$ : preobesity; $\geq 30$ : obesity class). Data on coffee intake was obtained asking the participants whether they had $<2$ cups/day or $\geq 2$ cups/day. Data on regular physical exercise was obtained asking the participants whether they exercised $\geq 3$ days a week and $\geq 20$ minutes/day. Data on alcohol consumption was obtained asking the participants whether they consumed $\geq 1$ drink/week.

Pittsburgh Sleep Quality Index (PSQI): Developed by Buysse et al [11] and validated to Turkish by Ağargün et al [12], PSQI assesses sleep quality within the last month by inquiring usual sleep habits through a scale comprising seven subscales with 19 questions (subjective sleep quality, time taken to fall asleep, total sleep time, habitual sleep efficiency, sleep disturbances, use of sleeping medication, and daytime dysfunction). Each question is evaluated on the basis of 0-3 points. A PSQI score of $\leq 5$ is considered as having a good sleep quality, and those with a PSQI score of $>5$ are evaluated as having a poor sleep quality.

Premenstrual Syndrome Scale (PMSS): Premenstrual Syndrome Scale is a reliable Likert scale which is widely used in Turkey. PMSS was developed and validated by Gençdoğan [13] in order to diagnose premenstrual syndrome and to specify the severity of premenstrual symptoms. It is based on the Diagnostic and Statistical Manual of Mental Disorders third edition (DSM III) and Diagnostic and Statistical Manual of Mental Disorders Revised fourth edition (DSM-IV-R). PMSS consists of 44 questions pertaining to the period a week prior to menstruation and 9 subscales (Depressive effect, Anxiety, Fatigue, Irritability, Depressive thoughts, Pain, Changes in appetite, Changes in sleeping habits, Bloating). The minimum and maximum scores which can be obtained from PMSS are 44 and 220, respectively. The participants having got a score $>110$ are diagnosed to have Premenstrual Syndrome. Additionally, it is agreed that as the score the patient obtains from the scale increases, so does the severity of PMS symptoms.

\section{Statistical analysis}

Statistical analysis was performed using Statistical Package for the Social Sciences Version 22.0 for Windows (SPSS Inc., Chicago, IL, USA). The comparison of two groups were performed with Mann-Whitney $U$ test and Pearson chi-square or Fisher's test for continuous and categorical variables, respectively. Univariate and multivariate analyses for sleep quality were performed using the binary logistic regression model. We reported two-sided $p$-values, and the $p$-values $<0.05$ were considered as statistically significant. 


\section{RESULTS}

A total of 265 women volunteered in this study. The median age of the participants was 30 (range: 18-45) years, and the median BMI was $22,1 \mathrm{~kg} / \mathrm{m}^{2}$ (range:14.6-45.1 kg/m².). The prevalence of PMS among the participants was $57 \%$ (n:150), and the median score of all participants' PMSS was 117 (range:41-216). The median PMSS scores of the participants with and without PMS were found to be 140 (range:111-216) and 87 (range:41-110), respectively. It was found that $24,5 \%$ ( $n: 65)$ of the participants consumed alcohol, 31\% (n:83) of them were smokers, $70 \%$ ( $n: 185)$ of them did not do regular physical exercise, and \%51 (n:134) of them had a coffee intake of $\geq 2$ cups/day. The median PSQI score of all participants was 5 (range: 0-18), the median time taken to fall asleep was 15 (range:1-120) minutes, and the mean total sleep time was $6.74 \pm 1.16$ hours. All demographic and lifestyle characteristics of the participants are shown in Table 1.

The participants were classified into two groups according to their PMSS scores; 150 (57\%) participants were classified in the group with PMS, and 115 (43\%) participants were classified in the group without PMS (Table 2).

It was found that the participants with PMS had significantly shorter total sleep time (mean:6.53 \pm 1.19 hours) than those without PMS (p:0.001). Also, they needed significantly longer time to fall asleep (median:20 minutes) than those without PMS $(p<0.001)$. The PSQI scores of the participants with PMS were significantly higher than those without PMS $(p<0.001)$, indicating poor sleep quality. It was observed that the participants with PMS had more coffee intake ( $p: 0.040)$ and more regular physical activity ( $\mathrm{P}: 0.009)$. There were no statistically significant correlation $(p>0.05)$ between the participants with PMS regarding their age, BMI (being overweight/obese), alcohol intake, or smoking habits.

The results obtained from logistic regression analysis are presented in Table3, where one can see that according to univariate analysis, patients without alcohol consumption history had a decreased risk for poor sleep quality (OR:0.50 95\% Cl:0.270.92, p:0.026). However, alcohol consumption was not associated with sleep quality in multivariate analysis. PMS positivity was associated with increased poor sleep quality in both univariate and multivariate analyses (OR:5.93 95\% Cl: 3.4610.15, $\mathrm{p}<0.001$; OR:5.61 95\% Cl: 3.19-9.88, $\mathrm{p}<0.001$, respectively). The remaining variables didn't have any statistically significant association with sleep quality.

\section{DISCUSSION}

We investigated the lifestyle factors associated with premenstrual syndrome (PMS) and the relation between PMS and quality of sleep. The prevalence of PMS among our participants was $57 \%$. No significant difference was found between the participants with and without PMS regarding their age, alcohol consumption, smoking habits, and being overweight. Participants with PMS were

Table 1. Demographic, life style and sleep characteristics of participants.

\begin{tabular}{|l|c|}
\hline Participant characteristics & $\begin{array}{c}\text { Median (Range) or } \\
\text { Number }(\%)\end{array}$ \\
\hline Age & $30(18-45)$ \\
\hline Body mass index & $22,1(14,6-45,1)$ \\
\hline BMI classification & $26(10 \%)$ \\
\hline Norderwieght & $188(71 \%)$ \\
\hline Pre-obesity & $34(13 \%)$ \\
\hline Obese class & $15(6 \%)$ \\
\hline PMS Status & \\
Without PMS & $115(43 \%)$ \\
With PMS & $150(57 \%)$ \\
PMSS Score & $117(41-216)$ \\
With PMS & $140(111-216)$ \\
Without PMS & $87(41-110)$ \\
\hline Alcohol consumption & \\
\hline Yes & $65(24,5 \%)$ \\
\hline No & $195(73,6 \%)$ \\
\hline Regular physical exercise & \\
\hline Yes & $80(30 \%)$ \\
No & $185(70 \%)$ \\
\hline Coffee intake & $131(49 \%)$ \\
\hline$\geq 2$ cups/day & $53(31 \%)$ \\
\hline$<2$ cups/day & $5(0-18)$ \\
\hline Cigarette Smoking & \\
\hline Yes & \\
No & \\
\hline PSQI score & \\
\hline BM: body mass index & \\
\hline
\end{tabular}

BMI: body mass index, PMS: premenstrual syndrome, PMSS: Premenstrual Syndrome Scale, PSQI: Pittsburgh Sleep Quality Index. 
Table 2. Characteristics of study participants with or without premenstrual syndrome.

\begin{tabular}{|c|c|c|c|}
\hline Patient characteristics & With PMS & Without PMS & $\mathrm{p}$-value \\
\hline Number of patients (\%) & $150(57 \%)$ & $115(43 \%)$ & \\
\hline Age & $29(18-43)$ & $31(19-45)$ & \\
\hline \multicolumn{4}{|l|}{ BMI group } \\
\hline Underweight & 15 & 12 & \multirow{4}{*}{0.946} \\
\hline Normal weight & 109 & 80 & \\
\hline Pre-obesity & 18 & 16 & \\
\hline Obese class & 8 & 7 & \\
\hline Time taken to fall asleep (minutes) & $20(2-120)$ & $10(1-60)$ & $<0.001^{*}$ \\
\hline Total Sleep time (hours) (mean \pm SD) & $6.53 \pm 1.19$ & $7.01 \pm 1.06$ & $0.001^{*}$ \\
\hline PSQI score (median; range) & $6(1-18)$ & $3(0-14)$ & $<0.001^{*}$ \\
\hline \multicolumn{4}{|l|}{ Alcohol consumption } \\
\hline Yes & $41(27 \%)$ & $24(21 \%)$ & \multirow{3}{*}{0.225} \\
\hline No & $109(73 \%)$ & $91(79 \%)$ & \\
\hline \multicolumn{3}{|l|}{ Cigarette Smoking } & \\
\hline Yes & 49 (33\%) & $34(30 \%)$ & \multirow{3}{*}{0,590} \\
\hline No & $101(67 \%)$ & $81(70 \%)$ & \\
\hline \multicolumn{3}{|l|}{ Regular physical exercise } & \\
\hline Yes & $55(37 \%)$ & $25(22 \%)$ & \multirow{3}{*}{$0.009^{*}$} \\
\hline No & $95(63 \%)$ & $90(78 \%)$ & \\
\hline \multicolumn{3}{|l|}{ Coffee intake } & \\
\hline$\geq 2$ cups/day & 83 (55\%) & $49(43 \%)$ & \multirow{2}{*}{$0.040^{*}$} \\
\hline$<2$ cups/day & 67 (45\%) & $66(57 \%)$ & \\
\hline
\end{tabular}

BMI: body mass index, PMS: premenstrual syndrome, PMSS: Premenstrual Syndrome Scale, PSQI: Pittsburgh Sleep Quality Index.

found to have a higher amount of coffee intake and regular physical activity. PSQI scores of the participants with PMS was higher, indicating a poor sleep quality. The participants with PMS had a statistically significant increase in reported time to fall asleep and a decrease in total sleep time. The results obtained from multivariate analysis showed that after controlling age, BMI, cigarette smoking, alcohol consumption, and regular physical activity, PMS had an association with increased risk for poor sleep and that the participants with PMS were 5 to 6 times more likely to have poor sleep than the participants without PMS. Thus, our data demonstrated that there is a meaningful relation between PMS and sleep quality and that PMS positivity is associated with increased poor sleep quality. Surprisingly, it was seen that BMI and alcohol consumption were not associated with poor sleep.

Various factors were suggested to have an association with PMS, two of them being coffee intake and regular physical activity $[4,5,14]$. Parallel with these findings, our results suggested that coffee intake ( $p: 0.040)$ and regular physical activity (p:0.009) were associated with PMS positivity. However, in a prospective study by Purdue et al [15] and a cross sectional survey by Farrokh-Eslamlou et al [16], it was argued that neither coffee intake nor regular physical exercise was associated with PMS. A report suggesting that PMS was more prevalent among athletes showed physical activity as a major risk factor. It was claimed in this report that the advanced practice of sports was an established factor for delaying the age of menarche and that late menarche was a well-known risk for PMS development [14]. However, we put forward another perspective on the increased prevalence of PMS among the women who are more physically active: exercising may be preferred for relieving the symptoms - as a way of self-treatment; thus, women with PMS might tend to exercise regularly. It was proven that yoga, aerobic exercise, and cardiorespiratory fitness were effective in decreasing the physical symptoms and severity of PMS [4, 17-19].

Our findings indicated that age, BMl, cigarette smoking, and alcohol consumption were not associated with PMS. It was reported that high 
Table 3. Univariate and Multivariate analysis of variables effecting sleep quality.

\begin{tabular}{|c|c|c|c|c|}
\hline Variables & $\begin{array}{l}\text { Univariable } \\
\text { OR }(95 \% \mathrm{Cl})\end{array}$ & P-value & $\begin{array}{c}\text { Multivariable } \\
\text { OR }(95 \% \mathrm{Cl})\end{array}$ & P-value \\
\hline \multicolumn{5}{|c|}{ Cigarette Smoking } \\
\hline Yes & 1 & 0.266 & 1 & 0.631 \\
\hline No & $0.73(0.43-1.26)$ & & $0.85(0.46-1.60)$ & \\
\hline \multicolumn{5}{|c|}{ Alcohol consumption } \\
\hline Yes & 1 & $0.026^{*}$ & 1 & 0.076 \\
\hline No & $0.50(0.27-0.92)$ & & $0.53(0.26-1.06)$ & \\
\hline \multicolumn{5}{|l|}{ Coffee intake } \\
\hline$\geq 2$ cups/day & 1 & 0.117 & 1 & 0.441 \\
\hline$<2$ cups/day & $0.67(0.41-1.10)$ & & $0.80(0.45-1.40)$ & \\
\hline \multicolumn{5}{|l|}{ PMS status } \\
\hline With PMS & $5.93(3.46-10.15)$ & $<0.001^{*}$ & $5.61(3.19-9.88)$ & $<0.001^{*}$ \\
\hline Without PMS & 1 & & 1 & \\
\hline Age & $0.96(0.93-1.00)$ & 0.095 & $0.97(0.93-1.01)$ & 0.268 \\
\hline \multicolumn{5}{|c|}{ BMI classification } \\
\hline Underwieght & 1 & 0.248 & 1 & 0.179 \\
\hline Normal weight & $0.65(0.27-1.58)$ & & $0.47(0.17-1.34)$ & \\
\hline Pre-obesity & $0.35(0.12-1.02)$ & & $0.26(0.07-0.90)$ & \\
\hline Obese class & $0.66(0.17-2.51)$ & & $0.65(0.14-2.95)$ & \\
\hline \multicolumn{5}{|c|}{ Regular Physical Exercise } \\
\hline Yes & 1 & 0.183 & 1 & 0.981 \\
\hline No & $0.69(0.40-1.19)$ & & $1.00(0.53-1.88)$ & \\
\hline
\end{tabular}

BMI: body mass index, PMS: premenstrual syndrome.

calorie intake, non-healthy dietary habits, alcohol consumption, and smoking have a major effect on PMS [5, 20, 21]. However, our results differ from such findings in that we did not screen any relation between smoking+alcohol consumption and PMS. No significant difference was observed in this respect. This discrepancy might have caused by the fact that alcohol consumption was low among our participants since our country is comprised mostly of Muslim people. Also, since this study was carried out on health care workers at a population of low smoking rate, we couldn't find any significant difference in this sense, either. Interestingly, there are conflicting data about BMI and its relation with PMS. Mizgier et al [3], Işık et al [5], and Şahin et al [7] found that $\mathrm{BMl}<25$ is a risk factor for PMS, but Bertone et al [22] claimed that elevation on $\mathrm{BMI}$ increases the PMS risk. According to BMI classification, neither being obese nor being underweight, normal weight or pre-obese was not found to be a risk factor for PMS in our study. This might be clarified by our participants weight distribution. Participants of our study were mainly in normal weight (with PMS 73\%, without PMS $70 \%$ ), and only a small number of them (less then
$10 \%)$ have obesity or are underweight, obesity constituting even a much smaller rate among two groups. Due probably to these reasons, we could not find any statistical significance regarding BMI.

Compared to men, women reported more problems with sleep, a problem mostly seen among those who had complaints of PMS and who was at the postmenopausal stage [23-25]. Our goal was to investigate the effect of PMS on sleep quality; therefore, we used a highly reliable and validated sleep questionnaire based on PSQI. We showed that the participants with PMS had significantly shorter total sleep time ( $p: 0.001)$ and needed significantly longer time to fall asleep $(p<0.001)$, and the PSQI scores of them were significantly higher $(p<0.001)$ than those without PMS, all indicating a poor sleep quality in PMS. PMS positivity was associated with increased poor sleep quality in both univariate and multivariate analysis (OR:5.93 95\% Cl: 3.46-10.15, $\mathrm{p}<0.001$; OR:5.61 95\% Cl: 3.19-9.88, $\mathrm{p}<0.001$, respectively). The results obtained from regression analysis demonstrated that the remaining lifestyle factors didn't have any statistically significant association 
with sleep quality. Our data was supported by Baker et al, who reported that sleep quality at the 3 premenstrual days was lower [10] and found that severe PMS led to poor sleep perception. However, this distribution of sleep due to severe PMS was not supported by polysomnography (PSG) findings $[26,27]$. Likewise, Özışık Karaman et al [28] argued that poor sleep was more common among PMS sufferers. All supportive data (in those studies) were assessed using PSQI, similar to our method. An epidemiologic study conducted in Sao Paulo on sleep showed that PMS positivity had poorer sleep quality [29]. Different from our data, they found that PMS positive participants had increased total sleep time [29]. Our data suggesting that participants with PMS had a shorter total sleep time were based on self-assessment, rather than PSG. An unfreshening sleep of a PMS sufferer may be felt shorter, which in turn may affect the participant's statement of total sleep time.

Putting the findings from previous studies and our results together, there is no doubt that PMS affects perception of sleep quality. This study adds a significant evidence of the presence of a correlation between PMS and sleep quality. Nevertheless, our study has some limitations. Because we did not evaluate the severity of PMS separately, we could not claim whether mild or severe PMS was related with poor sleep or not. Besides, although the PSQI questionnaire has been widely used and appears to be reliable for assessing sleep, we used only one sleep questionnaire and accepted questions about the absence of objective assessment of sleep by using polysomnography. Despite these limitations, our study is one of the largest surveys on PMS and sleep among adult women. Also, we obtained data on a wide range of additional potential PMS-related factors and have taken these into consideration while assessing the relation of PMS with sleep.

\section{CONCLUSION}

In conclusion, the present study highlights the important relation between PMS and sleep quality. Since PMS etiology still remains unclear, symptom relief constitutes the target of the treatment, which includes basic lifestyle modifications such as consumption of less coffee, avoidance of alcohol and smoking, and doing regular physical exercise. Relief of PMS complaints may lead to better sleep quality and enhancement of quality of life for a woman.

\section{CONFLICT Of INTEREST STATEMENT}

The authors declare that they have no conflict of interest

\section{ACKNOWLEDGEMENT}

We thank all the women health care workers who participated in this study.

\section{nee REFERENCES Cem}

[1] Ryu A, Kim TH. Premenstrual syndrome: A mini review. Maturitas 2015; 82(4): 436-440.

[2] Hofmeister S, Bodden S. Premenstrual Syndrome and Premenstrual Dysphoric Disorder. Am Fam Physician 2016; 94(3): 236-240.

[3] Mizgier M, Jarzabek-Bielecka G, Jakubek E, et al. The relationship between body mass index, body composition and premenstrual syndrome prevalence in girls. Ginekol Pol 2019; 90(5): 256-261.

[4] Dehnavi ZM, Jafarnejad F, Kamali Z. The Effect of aerobic exercise on primary dysmenorrhea: A clinical trial study. J Educ Health Promot 2018; 7: 3-5.

[5] Isik H, Ergol S, Aynioglu O, et al. Premenstrual syndrome and life quality in Turkish health science students. Turk J Med Sci 2016; 46(3): 695-701.
[6] Yoshimi K, Shiina M, Takeda T. Lifestyle Factors Associated with Premenstrual Syndrome: A Cross-sectional Study of Japanese High School Students. J Pediatr Adolesc Gynecol 2019; 32(6): 590-595.

[7] Sahin S, Ozdemir K, Unsal A. Evaluation of premenstrual syndrome and quality of life in university students. J Pak Med Assoc 2014; 64(8): 915-922.

[8] Cheng SH, Shih CC, Yang YK, et al. Factors associated with premenstrual syndrome - a survey of new female university students. Kaohsiung J Med Sci 2013; 29(2): 100105.

[9] Schiola A, Lowin J, Lindemann $M$, et al. The burden of moderate/severe premenstrual syndrome and premenstrual dysphoric disorder in a cohort of Latin American women. Value Health 2011; 14(5 Suppl 1): 93-95. 
[10] Baker FC, Driver HS. Self-reported sleep across the menstrual cycle in young, healthy women. J Psychosom Res 2004; 56(2): 239-243.

[11] Buysse DJ, Reynolds CF, 3rd, Monk TH, et al. The Pittsburgh Sleep Quality Index: a new instrument for psychiatric practice and research. Psychiatry Res 1989; 28(2): 193-213.

[12] Ağargün MY KH, Anlar Ö. Pittsburgh Uyku Kalitesi İndeksi'nin geçerliliği ve güvenirliği. Türk Psikiyatri Derg 1996; 7: 107-115.

[13] Gencdogan B. A new scale for premenstrual syndrome. Psychiatry in Turkey 2006; 8: 81-87.

[14] Czajkowska M, Drosdzol-Cop A, Galazka I, et al. Menstrual Cycle and the Prevalence of Premenstrual Syndrome/ Premenstrual Dysphoric Disorder in Adolescent Athletes. J Pediatr Adolesc Gynecol 2015; 28(6): 492-498.

[15] Purdue-Smithe AC, Manson JE, Hankinson SE, et al. A prospective study of caffeine and coffee intake and premenstrual syndrome. Am J Clin Nutr 2016; 104(2): 499507.

[16] Farrokh-Eslamlou H, Oshnouei S, Heshmatian B, et al. Premenstrual syndrome and quality of life in Iranian medical students. Sex Reprod Healthc 2015; 6(1): 23-27.

[17] Yesildere Saglam $H$, Orsal $O$. Effect of exercise on premenstrual symptoms: A systematic review. Complement Ther Med 2020; 48: 102272-9.

[18] Vaghela N, Mishra D, Sheth M, et al. To compare the effects of aerobic exercise and yoga on Premenstrual syndrome. J Educ Health Promot 2019; 8: 199.

[19] Haghighi ES, Jahromi MK, Daryano Osh F. Relationship between cardiorespiratory fitness, habitual physical activity, body mass index and premenstrual symptoms in collegiate students. J Sports Med Phys Fitness 2015; 55(6): 663-667.
[20] Hashim MS, Obaideen AA, Jahrami HA, et al. Premenstrual Syndrome Is Associated with Dietary and Lifestyle Behaviors among University Students: A Cross-Sectional Study from Sharjah, UAE. Nutrients 2019; 11(8): 1939-1957.

[21] Isgin-Atici K, Kanbur N, Akgul S, et al. Diet quality in adolescents with premenstrual syndrome: A crosssectional study. Nutr Diet 2019; 77(3): 351-358.

[22] Bertone-Johnson ER, Hankinson SE, Willett WC, et al. Adiposity and the development of premenstrual syndrome. J Womens Health (Larchmt) 2010; 19(11): 19551962.

[23] Hachul H, Andersen ML, Bittencourt LR, et al. Does the reproductive cycle influence sleep patterns in women with sleep complaints? Climacteric 2010; 3(6): 594-603.

[24] Jehan S, Auguste E, Hussain M, et al. Sleep and Premenstrual Syndrome. J Sleep Med Disord 2016; 3(5): 1061-76.

[25] Nowakowski S, Meers J, Heimbach E. Sleep and Women's Health. Sleep Med Res 2013; 4(1): 1-22.

[26] Baker FC, Kahan TL, Trinder J, et al. Sleep quality and the sleep electroencephalogram in women with severe premenstrual syndrome. Sleep 2007; 30(10): 1283-1291.

[27] Baker FC, Sassoon SA, Kahan T, et al. Perceived poor sleep quality in the absence of polysomnographic sleep disturbance in women with severe premenstrual syndrome. J Sleep Res 2012; 21(5): 535-545.

[28] Ozisik Karaman HI, Tanriverdi G, Degirmenci Y. Subjective sleep quality in premenstrual syndrome. Gynecol Endocrinol 2012; 28(8): 661-664.

[29] Nicolau ZFM, Bezerra AG, Polesel DN, et al. Premenstrual syndrome and sleep disturbances: Results from the Sao Paulo Epidemiologic Sleep Study. Psychiatry Res 2018; 264: 427-431. 